\title{
OPEN Wave types and energy conversion of impulse waves generated by landslides into mountain reservoirs
}

\begin{abstract}
Linfeng Han ${ }^{1,2 \bowtie}$, Pingyi Wang ${ }^{2} \&$ Tao Yu
Subaerial landslides sliding into shallow water are physically modeled in a three-dimensional wave basin. The generated impulse waves are highly nonlinear, and a large-scale splash zone is formed above the waves. Such impulse wave characteristics are different from those from landslides into deep water that are completely submerged after sliding. The recorded wave profiles included three wave types, namely nonlinear oscillatory wave, nonlinear transition wave and bore-like wave, mainly depending on the relative slide thickness and slide Froude number at impact. Bore-like waves were possible produced only by landslides into shallow water in three-dimensional experiments. The conversion rate of landslide kinetic energy at impact into the wave train energy is 1 to $18 \%$. Energy conversion characteristics are compared with other two- and three-dimensional studies on landslidegenerated waves and the results are discussed.
\end{abstract}

Landslides occurring at the bank of the reservoir can trigger impulsive waves that propagate both offshore and along the reservoir shoreline. The usually short propagation distance within mountain reservoirs leads to negligible wave attenuation thereby retaining the large damage potential for humans and the near reservoir infrastructure ${ }^{1}$. Damage caused by impulse wave run-up, for example, can extend to areas well-above the shoreline, endanger human life and cause major economic impacts. Dam overtopping can even result in reservoir failure and thus lead to catastrophic events. Historically, the highest wave run-up caused by impulse waves in reservoirs was observed in Vajont, North Italy in 1963. A rock flank failure of $250 \times 10^{6} \mathrm{~m}^{3}$ volume slid into the water body, displacing almost the entire reservoir volume. The slide caused a wave run-up of about $200 \mathrm{~m}$ at the opposite shore ${ }^{2}$. A recent event occurred in 2008 in the Three Gorges Reservoir Region, China. An impulse wave of $31.8 \mathrm{~min}$ height generated by the Gongjiafang landslide with a volume of $380,000 \mathrm{~m}^{3}$ caused a maximum run-up of $12.4 \mathrm{~m}$ at the opposite shore ${ }^{3}$. Field data from historic events are limited to the landslide scarp, run-up trimline, far-field tide gauge recordings and the submarine deposit, where mapped. Hence, physical modelling is an important method for studying the wave generation, propagation and run-up.

Methods of simulating the landslide have included two-dimensional models with a solid block sliding down an incline $e^{4-9}$ or with granular materials ${ }^{10-17}$, and three-dimensional models using a solid block slide ${ }^{18-25}$ or a granular landslide $\mathrm{e}^{26-29}$.

Although one order of magnitude smaller than tsunamis, the impulse waves in restricted waters (e.g., reservoirs, lakes and watercourses) may cause more serious consequences than ocean access. This is because in shallow water areas, the rock and soil mass has a stronger disturbance on the water body, and the behavior of the water is strongly nonlinear. In 2017 Huang et al. ${ }^{30}$, defined a partially submerged landslide after deposition as a landslide into shallow water. However, the previous research on landslide tsunamis mainly focuses on landslides into deep water that are completely submerged after sliding. Therefore, the present experiments were designed and conducted to fill this gap. Herein the attention is focused on the topic of wave type classification and energy conversion of landslide-generated impulse waves in shallow water in reservoirs.

\footnotetext{
${ }^{1}$ School of Civil Engineering, Chongqing Jiaotong University, Chongqing 400074, China. ${ }^{2}$ National Engineering Research Center for Inland Waterway Regulation, Chongqing Jiaotong University, Chongqing 400074,

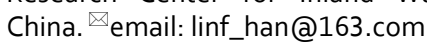




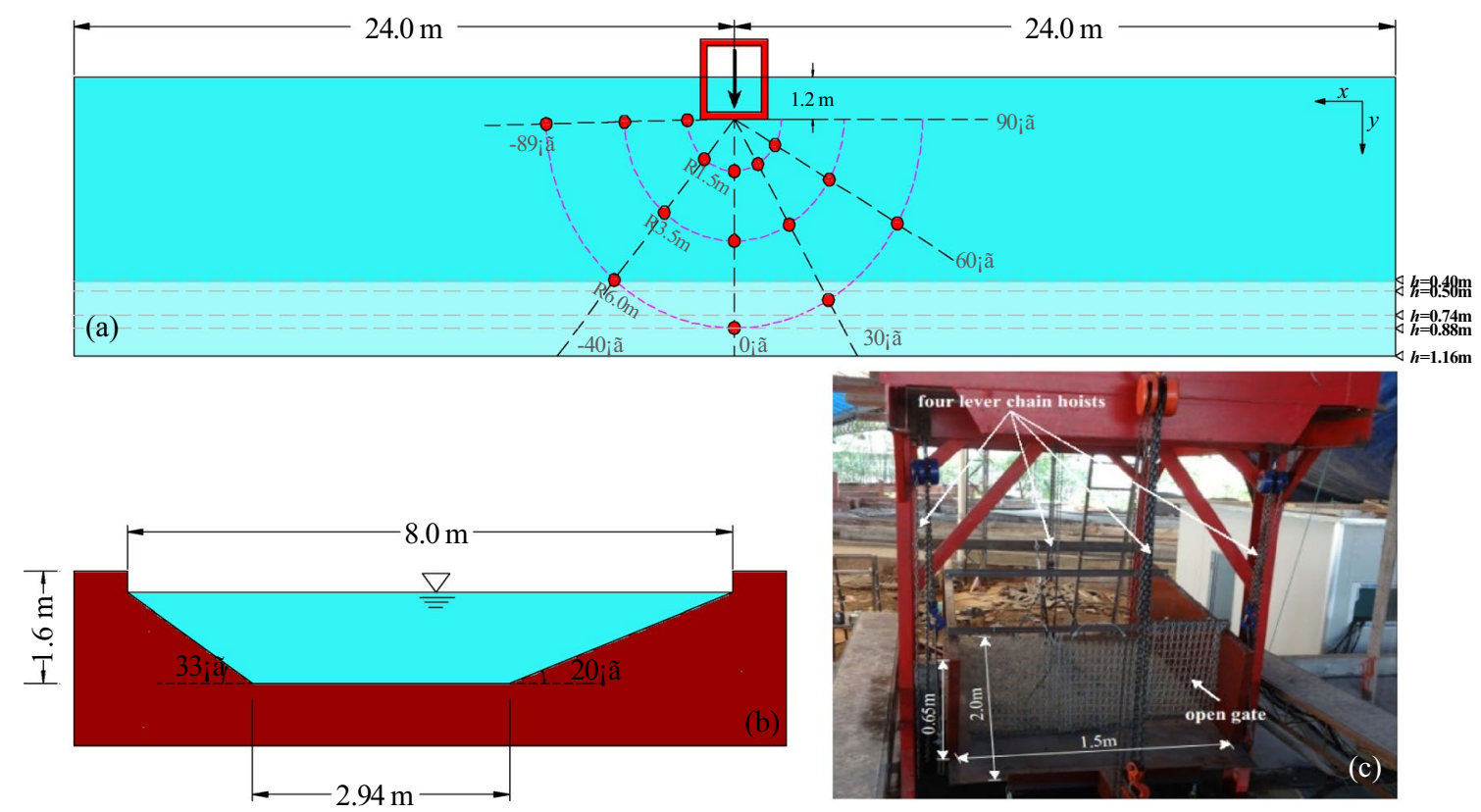

Figure 1. Sketch and picture of experimental set-up: (a) wave gauge array used to measure the water surface elevation of the landslide-generated tsunamis (red circles) with a water depth of $h=0.88$ or $1.16 \mathrm{~m}$. The gray dash lines correspond to water lines under different water depth conditions; (b) cross-sectional view of trapezoid dimensions for which water depth $h=1.6 \mathrm{~m}$ at bankfull flow; (c) chain hoist landslide tsunami generator.

\section{Physical model}

Experimental set-up. The physical experiments on impulse waves generated by landslide into shallow water were conducted in a three-dimensional wave basin. The concrete wave basin is $48 \mathrm{~m}$ long, with a trapezoid cross-section, which has a depth of $1.6 \mathrm{~m}$, a bottom width of $2.94 \mathrm{~m}$, top width of $8.0 \mathrm{~m}$, and both side slopes of $33^{\circ}$ (left bank) and $20^{\circ}$ (right bank), as shown in Fig. 1a,b. A chain hoist landslide tsunami generator was used to control the dynamic slide impact characteristics. The generator consists of a sliding box filled with up to $1.95 \mathrm{~m}^{3}$ of landslide material and four chain hoists that could adjust the precise location of collapse and hill slope angle effectively shown in Fig. 1c. As the gate opened, the landslide materials exited the slide box to accelerate solely by gravity towards the water surface. Landslide models with nine different volumes in the experiment were reported in $\mathrm{Mu}$ et $\mathrm{al}^{31}$. The test program included a variation of the still water depth $h=0.40,0.50,0.74,0.88$ and $1.16 \mathrm{~m}$, slide impact angle $\alpha=20^{\circ}, 40^{\circ}$ and $60^{\circ}$. A total of 135 experimental trials were conducted that covered a wide range of source volumes and reservoir depths.

The naturally occurring landslide due to the degradation of rock mass in the water level fluctuation zone is one of the main forms of a reservoir-induced landslide in the later stage of water storage and one of the important paths of newborn landslide generation ${ }^{32}$. Because they may be large and very rapid, rockslides related to reservoirs generally have been considerably more destructive than slope movements in surficial materials. According to the crack developments of the rock mass in the Three Gorges Reservoir area, the rockslide generated waves were physically modeled with a combination of rigid blocks with various scales on a planar hill slope. The density of the consisted block was set to $2400 \mathrm{~kg} / \mathrm{m}^{3}$ that matched the density of natural rock-soil masses, and the resulting rockslide model is shown in Fig. 2. Additional details on the experimental setup and rockslide evolution on the hill slope are reported in Han et al. ${ }^{33}$.

Instrumentation set-up. A high-speed overhead camera and several above water side-view videos were deployed on the subaerial landslide motion region and impact location to capture the landslide kinetic characteristics at a frequency of 1000 frames per second (fps). A total of 15 ultrasonic wave gauges were installed in the wave basin to record the water surface profiles in radial and angular direction away from the landslide source. The gauge has a resolution of $1 \mathrm{~mm}$ and a recording frequency of $100 \mathrm{~Hz}$. The wave probe located along the center line of wave basin at station $y=1.5 \mathrm{~m}$ was labeled as P1. In order to ensure the consistency of all tests, this paper sets the measured value from P1 gauge as the near-field maximum amplitude $a_{m}$. The gauge locations in the wave basin at water depth of $h=0.88$ and $1.16 \mathrm{~m}$ are shown in Fig. 1a. Since the recorded waves propagate over variable bathymetry, for low-water conditions, some gauges emplaced on the sloping walls of the wave basin cannot continue to work, so their position will be adjusted appropriately.

\section{Observations and analysis}

Impulse wave generation. The wave characteristics are dependent on the landslide impact parameters. The governing parameters for impulse waves generated by rock landslides in this study are the slide impact velocity $v_{s}$, still-water depth $h$, slide thickness $s$, slide width $w$, slide volume $V_{s}$. The corresponding dimensionless 

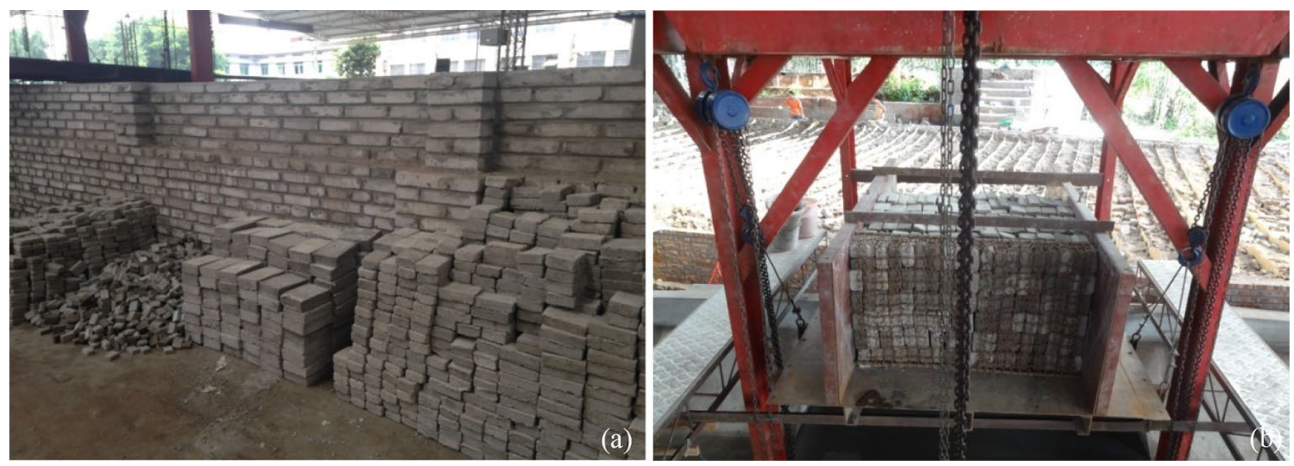

Figure 2. (a) Rigid concrete blocks; and (b) landslide model assembled with rigid blocks.

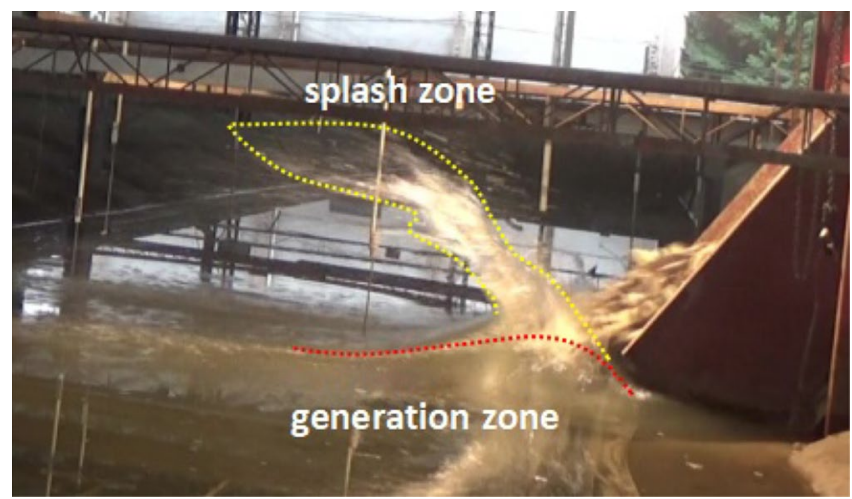

Figure 3. Photographs of propagating leading wave crest and water splashing in the near-field zone.

parameters are the slide Froude number $F=v_{s} /(g h)^{0.5}$, relative slide width $W=w / h$, relative slide thickness $S=s / h$, relative slide volume $V=V_{s} / h^{3}$. When the gate opens rapidly, the landslide material is released from the slide box and declines along the hill slope under gravity while decreasing the slide thickness and increasing the slide length and width. The porosity will increase due to the separation of rock mass during sliding. Across the bulk of the landslide width, the velocity is mostly uniform. The landslide front velocity is measured with side-view video and high-speed overhead camera. The velocity at impact is in the range $0.823<v_{s} /\left(g s_{0}\right)^{0.5}<1.836$ for the landslide volumes of $V_{s}=0.1 \mathrm{~m}^{3}$ to $0.9 \mathrm{~m}^{3}$, where $s_{0}$ is the initial slide thickness and $g$ is the gravitational acceleration.

Landslide-generated impulse wave is a complex phenomenon caused by the multi-phase interaction of slide mass, air and water ${ }^{34}$. In this experiment, the generation area of the near-field wave is within the range $0 \sim 1.45 \mathrm{~m}$ from the impact point. Immediately after the impact begins, the water is pushed up vertically by the slide and accompanied by splashing with the result that a surface splash zone is formed above the wave generation zone, as shown in Fig. 3. In shallow waters, landslide deposits lead to dramatic changes in channel topography, and the water body is quickly squeezed out of the water surface to form a water-jet. If the distance between the two sides of the reservoir or channel is short, the water-jet is likely to directly hit the opposing hillslope. As a dissipative item, the water body in the splash zone does not contribute to the wave generation, resulting in a low energy conversion rate from landslide to impulse waves in shallow-water areas, and a large part of the kinetic slide energy is consumed in the splash zone.

Wave energy conversion. The energy conversion describes the kinetic slide energy upon impact transferring to the generated wave energy. The kinetic slide impact energy is given as $E_{s}=(1 / 2) m_{s} v_{s}^{2}$, where $m_{s}$ is the slide mass, $v_{s}$ is the slide velocity at impact. The impulse wave energy involves two forms: kinetic energy $E_{k i n}$ and potential energy $E_{p o t}$. The wave potential energy per unit width of the recorded wavefront profiles is given as

$$
d E_{p o t}=\frac{1}{2} \rho_{w} g c \int_{0}^{T} \eta^{2} d t,
$$

where $\rho_{w}$ is the water density, $c$ is the wave celerity, $\eta$ is the water surface displacement. In the three-dimensional model, the impulse wave propagates in the form of a radial wave front, so the total wave potential energy of a radial wavefront at propagation distance $r$ in three-dimensional cylindrical coordinates $(-\pi / 2 \leq \theta \leq \pi / 2)$ can be expressed as 

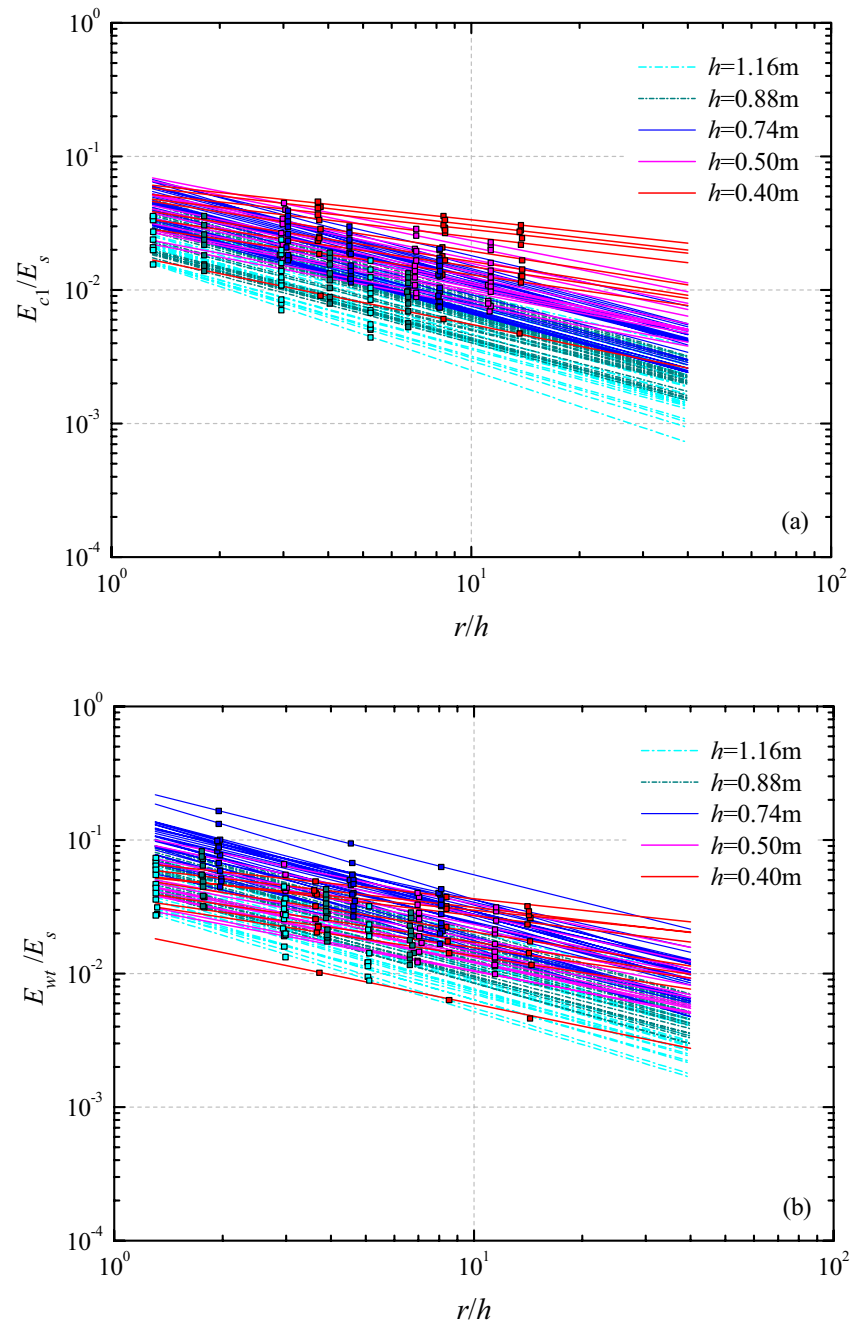

Figure 4. Attenuation of wave energy relative to kinetic slide impact energy with varying water depth for the (a) leading wave crest $E_{c r 1} / E_{s}$ and (b) wave train $E_{w t} / E_{s}$.

$$
E_{p o t}=\int_{-\pi / 2}^{\pi / 2}\left(\frac{1}{2} \rho_{w} g c \int_{0}^{T} \eta^{2} d t\right) r d \theta .
$$

In the case of only considering the initial wave crest potential energy, the integral range starts from zero and ends at the first down crossing point. Since the amplitudes of the trailing wave train are much smaller than that of the leading wave, the energy packet contained in the first three waves is used to computing the wave train energy in this paper. Mohammed and Fritz ${ }^{26}$ obtained the wave potential interpolation function of the leading wave crest by three-dimensional subaerial granular landslides, as follows

$$
d E_{p o t}(r, \theta)=k_{E_{c 1}} r^{n} \cos ^{2} \theta
$$

within the wave propagation range $0 \leq r \leq r_{\max }$ and $-\pi / 2 \leq \theta \leq \pi / 2$, where $n$ represents the amplitude decay rate. Since the movement of water particles in the water column is difficult to measure, the generated wave kinetic energy cannot be directly estimated. At present, the equipartition assumption $\left(E_{k i n} \approx E_{p o t}\right)$ in linear waves is often used to calculate total wave energy. In $1985 \mathrm{Williams}^{35}$, found that when the solitary wave height is close to the breaking limit, the total wave energy $\left(E_{t o t}=E_{p o t}+E_{k i n}\right)$ obtained by numerical calculation may exceed $11 \%$ of the equipartition assumption. But this result is typically only a few percent in the current study. Therefore, the total wave energy of the leading wave crest can be expressed as

$$
E_{c r 1}=\int_{-\pi / 2}^{\pi / 2}\left(\rho_{w} g c \int_{0}^{T_{c r 1}} \eta^{2} d t\right) r d \theta,
$$

where $T_{c r 1}$ is the period of the leading wave crest from the initial rise to the first down-crossing. As shown in Fig. $4 \mathrm{a}$, the energy conversion from kinetic slide impact energy to leading wave crest with a rockslide on a planar hill slope is between 0.5 and $7 \%$. Under the influence of wave energy dispersion and frictional dissipation, the 


\begin{tabular}{|c|c|c|c|}
\hline Study & Model type & $E_{c 1} / E_{s}$ & $E_{w t} / E_{s}$ \\
\hline Kamphuis and Bowering ${ }^{4}$ & 2D block model & - & $10-50 \%$ \\
\hline Huber $^{36}$ & 2D granular slide model & - & $1-40 \%$ \\
\hline Watts $^{6}$ & 2D block model (underwater) & - & $2-13 \%$ \\
\hline Fritz et al. ${ }^{12}$ & 2D granular slide model & $2-30 \%$ & $4-50 \%$ \\
\hline Ataie-Ashtiani and Nik-Khah ${ }^{37}$ & 2D block model & - & $5-50 \%$ \\
\hline Heller and Hager ${ }^{15}$ & 2D granular slide model & - & $11.3-85.7 \%$ \\
\hline Mohammed and Fritz ${ }^{26}$ & 3D gravel slide model & $0.5-3 \%$ & $1-15 \%$ \\
\hline McFall and Fritz ${ }^{29}$ & 3D cobble slide model & $0.5-11 \%$ & $1-24 \%$ \\
\hline Current study & 3D rock slide model & $0.5-7 \%$ & $1-18 \%$ \\
\hline
\end{tabular}

Table 1. Experimental model studies of energy conversion between the landslide kinetic energy and the generated impulse waves.

energy of the initial wave crest decreases with the propagation distance. Since the wave celerity of the waves in the wave train is different, the total wave train energy can only be obtained by the superposition of the wave energy of the each individual wave amplitude. For landslide-generated waves, the wave energy of the trailing wave train is negligible relative to main wave. In the present experiments, the energy packet contained in the first three waves is used to calculate the wave train energy. The energy conversion from kinetic slide impact energy to wave train with a rockslide on a planar hill slope is between 1 and $18 \%$ as shown in Fig. 4b. Table 1 includes studies in which the energy conversion between landslide kinetic energy and generated wave energy from different model types were investigated. From Table 1 the energy conversion from kinetic energy at slide impact to wave energy in the $2 \mathrm{D}$ models is much greater than in the $3 \mathrm{D}$ models. The $2 \mathrm{D}$ models result in high energy conversion rates as lateral constraint on the landslide motion and wave generation. In contrast, the 3D models don't have lateral constraint on landslide and water body, which increases granular landslide deformation and triggers lateral escape of water body, thereby decreasing the energy conversion from landslide impact to generated waves. In addition, the energy conversion rates are slightly larger in this study than in the 3D experiments of Mohammed and Fritz ${ }^{26}$ and Mcfall and Fritz ${ }^{29}$. Compared with 3D rock slide models, the 3D granular landslides undergo greater slide deformation during the subaerial and subaqueous movement, thereby dissipating more slide energy through internal frictional effects and decreasing the energy conversion during impact.

In the energy conversion process of sliding energy to wave train, the energy conversion rate in shallow water area is generally lower than that in deep water area. This is because it takes a short time form landslide impact water body to initial wave generation. Therefore, when the slide volume is relatively larger than the receiving water body, the landslide will deposit rapidly after entering the water, resulting in a large amount of slide impact energy that cannot be transformed into impulse waves. In addition, due to the incompressibility of the water body, the part of the energy that is not involved in wave making forms a water jet-flow with a lot of splashing above the wave generation zone, as shown in Fig. 3. As a dissipation term, the water body in the splash zone does not participate in the wave making process, which leads to a lower energy conversion rate in shallow-water areas than in deep-water areas.

Wave profiles. According to the study's results of two-dimensional block slide experiments by Noda ${ }^{38}$ and two-dimensional granular slide experiments by Fritz et al. ${ }^{12}$, impulse waves generated by landslides were classified into nonlinear oscillatory waves, nonlinear transition waves, solitary-like waves and dissipative transient bores based on the landslide Froude number and relative slide thickness at impact. However, Mohammed and Fritz ${ }^{26}$ and MacFall and Fritz ${ }^{29}$ only found two wave types, nonlinear oscillatory and nonlinear transition by their three-dimensional experiments. Solitary and bore-like waves were not observed in above studies because the additional degree of freedom in three-dimensional granular models increases landslide deformation, thereby reducing the slide thickness at impact.

In the present three-dimensional experiments, we have not only observed nonlinear oscillatory and nonlinear transition type of waves but also observed bore-like waves in some cases of landslides into shallow water. Figure 5a shows a recorded nonlinear oscillatory wave profile with slide parameters $F=0.74, S=0.17, V=0.19$, $h=1.16 \mathrm{~m}$. This wave type has a leading main wave crest followed by a strong dispersive oscillatory wave train, and the strong dispersion characteristic can stretch the wave train and transiently enhance trailing waves during propagation. This study found that nonlinear oscillatory waves are generated by relatively slower and thinner landslides. Figure 5b shows a recorded nonlinear transition wave profile with slide parameters $F=1.63, S=0.81$, $V=2.22, h=0.74 \mathrm{~m}$. This wave type is characterized by a main leading wave crest and a long shallow trough followed by a weakly dispersive wave train. The experiment found that nonlinear transition waves are generated by relatively faster and thicker landslides. Figure $5 c$ shows a recorded bore-like wave profile with slide parameters $F=2.13, S=1.5, V=9.38, h=0.4 \mathrm{~m}$. Compared with other types of waves, the energy conversion from impacting slide mass to generated bore-like wave is energetically inefficient. Nevertheless, the bore-like waves generated by landslides often have a relatively large amplitude in the near-field area because these waves are characterized by steep wave front, flat wave tail and entraining amount of air. Heller and Hager ${ }^{15}$ found that the near-field maximum amplitude of bore wave can be as high as 2.5 times the still water depth $h$. The observed bore-like waves were in intermediate to shallow water range and generated by fast and thick landslides. Therefore, for impulse 

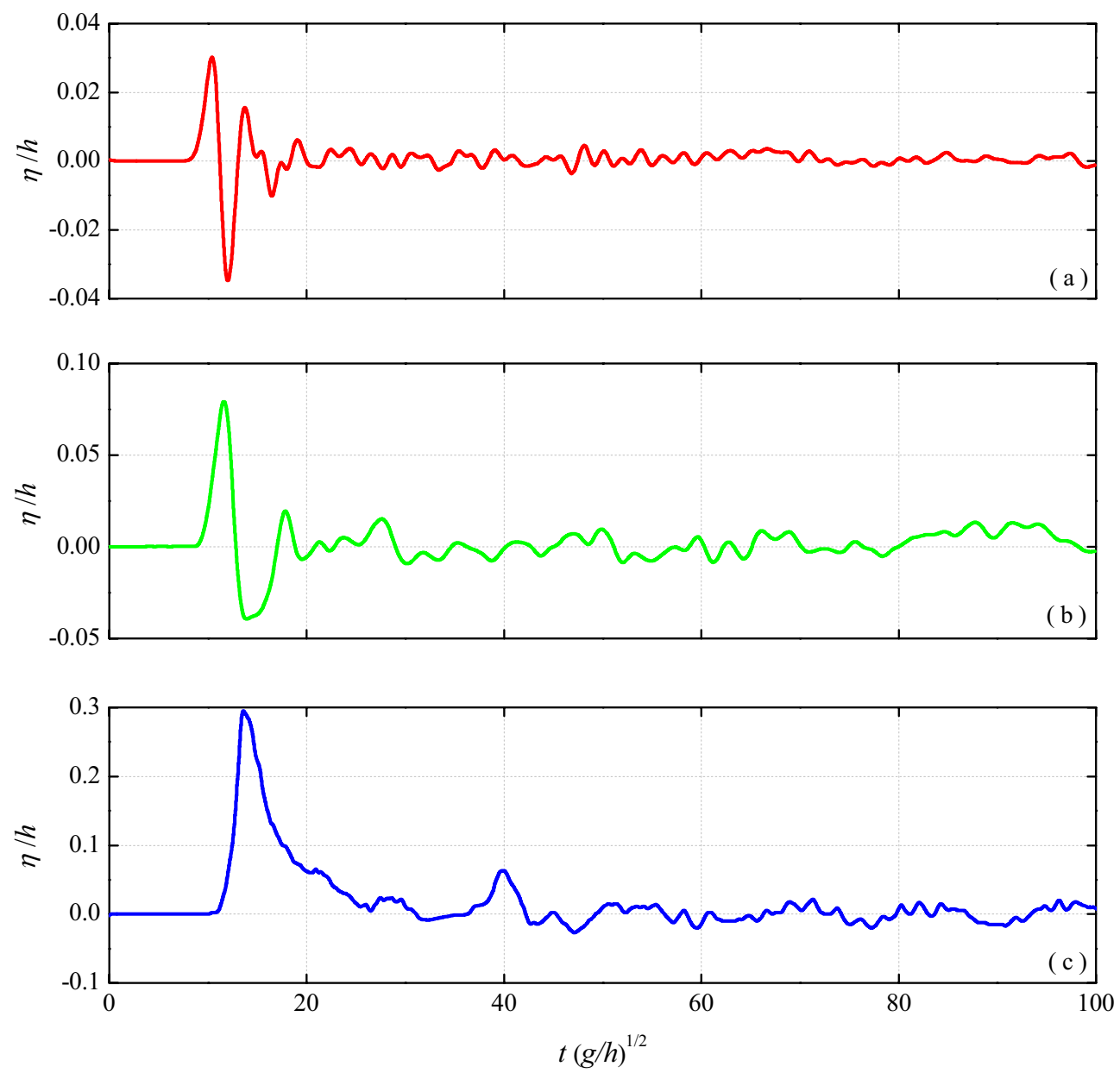

Figure 5. Illustration of three types of waves observed by P1 probe: (a) nonlinear oscillatory wave profiles with slide parameters $F=0.74, S=0.17, V=0.19, h=1.16 \mathrm{~m}$; (b) nonlinear transition wave profiles with slide parameters $F=1.63, S=0.81, V=2.22, h=0.74 \mathrm{~m}$; (c) bore-like wave profiles with slide parameters $F=2.13$, $S=1.5, V=9.38, h=0.4 \mathrm{~m}$.

wave events generated by landslides into shallow water such as reservoirs and lakes, more attention should be paid to the possible bore-like waves.

All observed wave trains expand outward as the propagation distance due to nonlinearity and dispersion. The leading waves attenuate as the propagation distance, while dispersion temporarily enhances subsequent trailing waves ${ }^{39}$. In this study, the observed three wave-type regions are shown in Fig. 6 . The wave-type region was determined by the slide Froude number $F$ and the relative slide thickness $S$. Compared with three-dimensional granular landslide experiments by Mohammed and $\mathrm{Fritz}^{26}$, the transition from nonlinear oscillatory to nonlinear transition wave-type region in present study requires relatively higher values of dimensionless parameters $F$ and $S(F=7.5-7.5 S)$. Bore-like waves were generated by landslides with larger values of $F$ and $S$ than those producing a nonlinear transition wave. A bore-like wave as the leading wave was observed if the slide Froude number satisfied the empirical relationship $F \geq(12-8 S)$. Hence, the bore-like waves were generated by thick landslide relative to water depth at a large slide Froude number.

\section{Conclusions}

Based on the Froude similitude, impulse waves induced by three-dimensional rock landslides are physically modeled, and the wave types and energy conversion of subaerial landslide generated impulse waves were investigated. The main results may be summarized as follows:

(1) Compared with two-dimensional models, three-dimensional granular landslides have a larger amount of deformation due to the lack of lateral constraints during slide, thus reducing the effectiveness of energy conversion and wave generation. Between 0.5 and $7 \%$ of the landslide kinetic energy is converted to the leading wave crest and 1 to $18 \%$ is converted the wave train. For the cases of landslides into shallow water, big wave splash forming above the wave generation zone consumes a large amount of landslide energy, resulting in a smaller energy conversion than a landslide into deep water. 


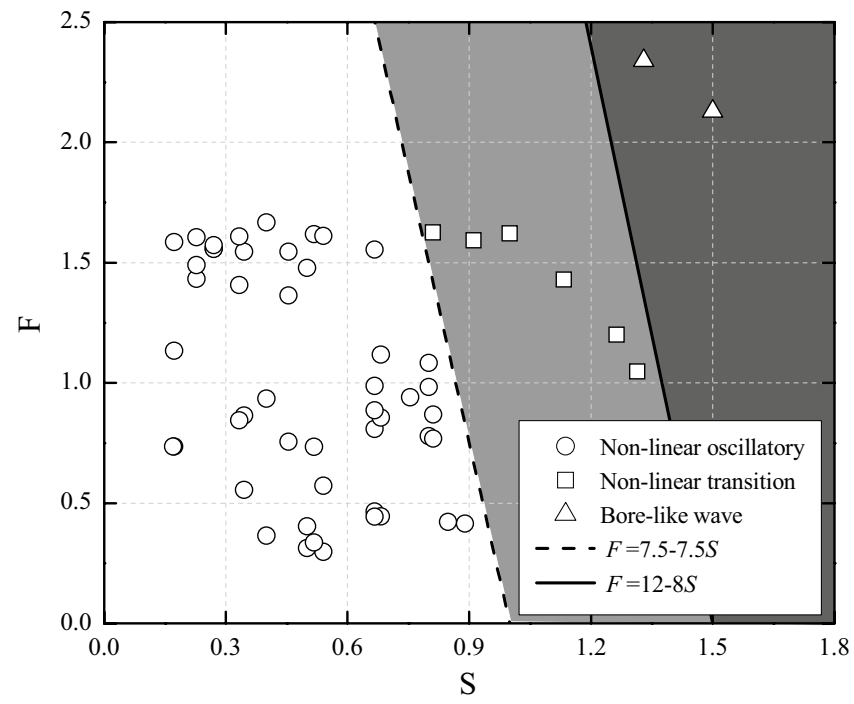

Figure 6. Observed wave type classification based on the slide Froude number $F=v_{s} /(g h)^{0.5}$ and relative slide thickness $S=s / h$.

(2) Three wave types were observed: nonlinear oscillatory wave, nonlinear transition wave and bore-like wave, depending mainly on the relative slide thickness $S=s / h$ and the slide Froude number $F=v_{s} /(g h)^{1 / 2}$. Nonlinear oscillatory waves result generally from small dimensionless parameters $F$ and $S$. They consist of a leading main wave crest followed by a strong dispersive oscillatory wave train. Nonlinear transition waves involve generally medium to large dimensionless parameters $F$ and $S$. They consist of a major leading wave crest and a long shallow trough, followed by a weakly diffuse wave train. Bore-like waves result generally from large dimensionless parameters $F$ and $S$. They consist of one dominant wave with a large amount of air at the wave front. In three-dimensional experiments, only landslides into shallow water could produce bore-type wave profiles.

Impulse wave events generated by landslides into shallow water occur widely in restricted waters such as reservoirs, lakes and watercourses, and such impulse waves often cause large disasters. The classification of impulse waves in shallow water may be simply applied to practical predictions since it depends directly on basic parameters, which is useful for disaster mitigation of reservoirs.

Received: 1 September 2021; Accepted: 28 February 2022

Published online: 08 March 2022

\section{References}

1. Fuchs, H. \& Hager, W. H. Solitary impulse wave transformation to overland flow. J. Waterw. Port Coast. Ocean Eng. 141(5), 04015004. https://doi.org/10.1061/(ASCE)WW.1943-5460.0000294 (2015).

2. Panizzo, A., De Girolamo, P., Di Risio, M., Maistri, A. \& Petaccia, A. Great landslide events in Italian artificial reservoirs. Nat. Hazard Earth Syst. 5, 733-740 (2005).

3. Huang, B. et al. Analysis of waves generated by Gongiafang landslide in Wu Gorge, Three Gorges Reservoir, on November 23, 2008. Landslides 9(3), 395-405 (2012).

4. Kamphuis, J. W., Bowering, R. J. Impulse waves Generated by Landslides, Paper Presented at Twelfth Coastal Engineering Conference (Coastal Eng Res Counc, 1970).

5. Heinrich, P. Nonlinear water waves generated by submarine and aerial landslides. J. Waterw. Port Coast. Ocean Eng. 118(3), 249-266 (1992).

6. Watts, P. Tsunami features of solid block underwater landslides. J. Waterw. Port Coast. Ocean Eng. 126(3), 144-152 (2000).

7. Najafi-Jilani, A. \& Ataie-Ashtiani, B. Estimation of near-field characteristics of tsunami generation by submarine landslide. Ocean Eng. 35(5), 545-557 (2008).

8. Sælevik, G., Jensen, A. \& Pedersen, G. Experimental investigation of impact generated tsunami; related to a potential rock slide, western Norway. Coast. Eng. 56(9), 897-906 (2009).

9. Heller, V. \& Spinneken, J. Improved landslide-tsunami prediction: Effects of block model parameters and slide model. J. Geophys. Res. Oceans 118(3), 1489-1507 (2013).

10 Fritz, H. M., Hager, W. H. \& Minor, H.-E. Landslide generated impulse waves. 1. Instantaneous flow fields. Exp. Fluids 35(6), 505-519 (2003).

11 Fritz, H. M., Hager, W. H. \& Minor, H.-E. Landslide generated impulse waves. 2. Hydrodynamic impact craters. Exp. Fluids 35(6), 520-532 (2003).

12. Fritz, H. M., Hager, W. H. \& Minor, H.-E. Near field characteristics of landslide generated impulse waves. J. Waterw. Port Coast. Ocean Eng. 130(6), 287-302 (2004).

13. Zweifel, A., Hager, W. H. \& Minor, H.-E. Plane impulse waves in reservoirs. J. Waterw. Port Coast. Ocean Eng. 132(5), 358-368 (2006).

14. Heller, V., Hager, W. H., Minor, H. E. Landslide Generated Impulse Waves in Reservoirs: Basics and Computation (VAW Publication, ETH Zurich, 2009). 
15. Heller, V. \& Hager, W. H. Impulse product parameter in landslide generated impulse waves. J. Waterw. Port Coast. Ocean Eng. 136(3), 145-155 (2010).

16. Lindstrøm, E. K. Waves generated by subaerial slides with various porosities. Coast. Eng. 116(10), 170-179 (2016).

17. Miller, G. S., Take, W. A., Mulligan, R. P. \& McDougall, S. Tsunamis generated by long and thin granular landslides in a large flume. J. Geophys. Res. Oceans 122(1), 653-668 (2017).

18. Liu, P.L.-F., Wu, T.-R., Raichlen, F., Synolakis, C. E. \& Borrero, J. C. Runup and rundown generated by three-dimensional sliding masses. J. Fluid Mech. 536(1), 107-144 (2005).

19 Panizzo, A., De Girolamo, P. \& Petaccia, A. Forecasting impulse waves generated by subaerial landslides. J. Geophys. Res. Space https://doi.org/10.1029/2004JC002778 (2005).

20. Enet, F. \& Grilli, S. T. Experimental study of tsunami generation by three-dimensional rigid underwater landslides. J. Waterw. Port Coast. Ocean Eng. 133(6), 442-454 (2007).

21. Di Risio, M. et al. Landslide-generated tsunamis runup at the coast of a conical island: New physical model experiments. J. Geophys. Res. Oceans 114, C01009. https://doi.org/10.1029/2008JC004858 (2009)

22. Di Risio, M., Bellotti, G., Panizzo, A. \& De Girolamo, P. Three-dimensional experiments on landslide generated waves at a sloping coast. Coast. Eng. 56(5-6), 659-671 (2009).

23. Lindstrøm, E. K., Pedersen, G. K., Jensen, A. \& Glimsdal, S. Experiments on slide generated waves in a 1:500 scale ford model. Coast. Eng. 92(10), 12-23 (2014).

24. Wang, W. et al. Modeling of landslide generated impulsive waves considering complex topography in reservoir area. Environ. Earth Sci. https://doi.org/10.1007/s12665-016-5252-y (2016).

25. Romano, A. et al. Tsunamis generated by landslides at the coast of conical islands: Experimental benchmark dataset for mathematical model validation. Landslides 13(6), 1-15 (2016).

26. Mohammed, F. \& Fritz, H. M. Physical modeling of tsunamis generated by three-dimensional deformable granular landslides. J. Geophys. Res. Oceans 117, C11015. https://doi.org/10.1029/2011JC007850 (2012).

27. Huang, B. et al. A physical similarity model of an impulsive wave generated by Gongjiafang landslide in Three Gorges Reservoir, China. Landslides 11(3), 513-525 (2014).

28. Heller, V. \& Spinneken, J. On the effect of the water body geometry on landslide-tsunamis: Physical insight from laboratory tests and 2D to 3D wave parameter transformation. Coast. Eng. 104(10), 113-134 (2015).

29. McFall, B. C. \& Fritz, H. M. Physical modelling of tsunamis generated by three-dimensional deformable granular landslides on planar and conical island slopes. Proc. R. Soc. A 472(2188), 20160052. https://doi.org/10.1098/rspa.2016.0052 (2016).

30. Huang, B., Wang, S. \& Zhao, Y. Impulse waves in reservoirs generated by landslides into shallow water. Coast. Eng. 123(5), 52-61 (2017).

$31 \mathrm{Mu}$, P. et al. The propagation of landslide-generated impulse waves and their impacts on the moored ships: An experimental investigation. Adv. Civ. Eng. https://doi.org/10.1155/2020/6396379 (2020).

32. Yin, Y., Huang, B., Zhang, Q., Yan, G. \& Dai, Z. Research on recently occurred reservoir-induced Kamenziwan rockslide in Three Gorges Reservoir, China. Landslides 17(2), 1-15 (2020).

33. Han, L., Wang, P., Mu, P., Ren, Q. \& Liu, Y. Experimental investigation of propagation and run-up of rockslide-generated impulse waves in a curved mountain reservoir. Nat. Hazards https://doi.org/10.1007/s11069-021-05099-5 (2021).

34. Kim, G.-B. et al. Three dimensional landslide generated tsunamis: Numerical and physical model comparisons. Landslides 17, $1145-1161(2020)$.

35. Williams, J. M. Tables of Progressive Gravity Waves (Pitman Advanced Pub. Program, 1985).

36. Huber, A. Schwallwellen in Seen als Folge von Bergstürzen. VAW-Mitteilung 47, (ed. Vischer, D.) Versuchsanstalt für Wasserbau, Hydrologie und Glaziologie (ETH Zürich, 1980) (in German)

37. Ataie-Ashtiani, B. \& Nik-Khah, A. Impulsive waves caused by subaerial landslides. Environ. Fluid Mech. 8(3), 263-280 (2008).

38. Noda, E. Water waves generated by landslides. J. Waterw. Port Coast. Ocean Eng. 96(4), 835-855 (1970).

39 Løvholt, F., Pedersen, G. \& Gisler, G. Oceanic propagation of a potential tsunami from the La Palma Island. J. Geophys. Res. Oceans https://doi.org/10.1029/2007JC004603 (2008).

\section{Acknowledgements}

This research was supported by the National Natural Science Foundation of China (Grant52009014), Scientific and Technological Research Program of Chongqing Municipal Education Commission (Grant KJQN202000709), Natural Science Foundation of Chongqing, China (Grant cstc2020jcyj-bshX0101). Support by the scientific personnel and technical staff at the National Engineering Research Center for Inland Waterway Regulation, Chongqing Jiaotong University, Chongqing, is acknowledged.

\section{Author contributions}

L.H. and P.W. conceived and designed the analysis, L.H. wrote the main manuscript text, and Y.T. collected the data. All authors reviewed the manuscript.

\section{Competing interests}

The authors declare no competing interests.

\section{Additional information}

Correspondence and requests for materials should be addressed to L.H.

Reprints and permissions information is available at www.nature.com/reprints.

Publisher's note Springer Nature remains neutral with regard to jurisdictional claims in published maps and institutional affiliations. 
(c) (i) Open Access This article is licensed under a Creative Commons Attribution 4.0 International cc) License, which permits use, sharing, adaptation, distribution and reproduction in any medium or format, as long as you give appropriate credit to the original author(s) and the source, provide a link to the Creative Commons licence, and indicate if changes were made. The images or other third party material in this article are included in the article's Creative Commons licence, unless indicated otherwise in a credit line to the material. If material is not included in the article's Creative Commons licence and your intended use is not permitted by statutory regulation or exceeds the permitted use, you will need to obtain permission directly from the copyright holder. To view a copy of this licence, visit http://creativecommons.org/licenses/by/4.0/.

(C) The Author(s) 2022 